\title{
Clinico-pathological response of mice following oral route infection of $C$. pseudotuberculosis
}

\author{
Jesse, F.F.A* ${ }^{* 1,3}$, Randolf, P.S.S ${ }^{1}$, Saharee, A.A ${ }^{1}$, Wahid, A.H ${ }^{1}$, \\ Zamri-Saad, $\mathrm{M}^{3}$, Jasni, $\mathrm{S}^{1}$, Omar, A.R ${ }^{2,4}$, Adamu, $\mathrm{L}^{1}$ and Abdinasir, Y. O ${ }^{1}$ \\ ${ }^{I}$ Department of Veterinary Clinical Studies, Faculty of Veterinary Medicine, Universiti Putra Malaysia, 43400 \\ UPM Serdang, Selangor, Malaysia \\ ${ }^{2}$ Department of Veterinary Pathology and Microbiology, Faculty of Veterinary Medicine, Universiti Putra \\ Malaysia, 43400 UPM Serdang, Selangor, Malaysia \\ ${ }^{3}$ Research Centre for Ruminant Disease, Universiti Putra Malaysia, 43400 UPM Serdang, Selangor, Malaysia \\ ${ }^{4}$ Institute of Bioscience, Universiti Putra Malaysia, 43400 UPM Serdang, Selangor, Malaysia
}

\begin{abstract}
Corynebacterium pseudotuberculosis is a facultative, rod shaped, gram-positive bacteria which is the causative agent of caseous lymphadenitis (CLA). CLA is a chronic granulomatous infectious disease that is characterized by formation of abscesses typically located in superficial lymph nodes and lungs. Difficulties in early diagnosis of CLA infected animals have limited the effectiveness of controlling and eradicating the disease. The aim of the present study was to acquire a better way of understanding the pathogenesis of CLA via oral route infection in a mouse model. A total of sixteen healthy mice $(n=16)$ were divided equally into 2 groups, where the first group of mice were orally inoculated with $1.0 \mathrm{~mL}$ of sterile phosphate buffer solution $(P B S), p H 7$, and the second group of mice were orally inoculated with $1.0 \mathrm{~mL}$ of $10^{9}$ colony forming unit (cfu) of C. pseudotuberculosis. Clinical signs and histopathological changes in visceral organs were compared between the diseased and non-diseased group within the period of 120 hours of post inoculation. Results of this study showed that there were no significant $(P>0.05)$ changes in clinical signs observed between diseased and non-diseased group. However, there were significant $(P<0.05)$ histopathological changes observed in the visceral organs( lung, liver and kidney) between diseased and non-diseased group where the visceral organs had severe congestion and increased vascularization, micro-abscesses formation, infiltration of neutrophils and macrophages, tubercular granulomas, necrosis and early signs of degeneration as compared to the nondiseased group.
\end{abstract}

Keywords: C. pseudotuberculosis, caseous lymphadenitis (CLA), mice, clinical response, cellular changes

\section{Introduction}

Caseous lymphadenitis (CLA) is common and chronic disease that prevalent in the entire world's major sheep and goat production areas [1-3]. It is mainly characterized by the formation of abscesses, typically located in superficial lymph nodes (cutaneous form), and internal lymph nodes and organs (visceral form) [4-6]. The causal pathogen of CLA is Corynebacterium pseudotuberculosis, a rod shape, gram-positive, non-spore forming bacteria. It is a facultative intracellular parasite that is found on fomites, in soil and manure contaminated with prudent exudate [7]. Because of the chronic, subclinical nature and the presence of the viable bacteria inside capsulated abscess of infected animals, the control of the disease (CLA) with antimicrobial or antibiotics becomes completely challenging $[8,9,1]$. Thus, its prevalence is rising particularly in developing countries. However, the disease causes significant economic losses in the small ruminant industry [10]. In Malaysia, CLA is a potential threat to the livestock industry causing several negative impacts on both productivity and fertility of small ruminant herds.

Therefore, this study was conducted to acquire a better way of understanding CLA in subclinical cases through mouse model. Furthermore, there is a lack of information on the pathogenesis and clinical signs of CLA in mouse model via oral route infection. Moreover, information on host cellular response in mice following oral route inoculation of $C$. pseudotuberculosis is insufficient. Thus, the objective of the present study was to determine whether there were similar developments of clinical signs together with pathological changes in mice following the oral route inoculation with reference to actual cases that occur in small ruminants (sheep and goat).

Animals

\section{Materials And Methods}

Sixteen Balb/c mice of both sexes, aged 3-4 weeks were obtained from Institute of Cancer Research (ICR), Kuala Lumpur, Malaysia. The mice were housed at the Animal Experimentation Unit (AEU), which was 
maintained at $21-23{ }^{\circ} \mathrm{C}$. As they were kept in stocking density of 4 mice/cage, fed a commercial lab animal pellet and provided water which was freely available for an acclimatization period of 1 week before the beginning of the studies. All experiments were conducted under protocols approved by the Animal Experimentation Ethics Committee (AEEC), Faculty of Veterinary Medicine, Universiti Putra Malaysia (UPM).

\section{Bacteria}

A stock culture of $C$. pseudotuberculosis made from a lymph node that was naturally infected with caseous lymphadenitis from previous outbreak of CLA in the animal farm of University Putra Malaysia (UPM) was used to prepare the inoculums. The Organism was cultured onto blood agar and incubated at $37^{\circ} \mathrm{C}$ for 24h.Thereafter, the organism was sub-cultured in Brain Heart Infusion (BHI) broth for $24 \mathrm{~h}$ and concentration were estimated to the standard dose of $1 \times 10^{9}$ colony-forming units $/ \mathrm{ml}(\mathrm{CFU})$ using the Mac Farland technique.

\section{Experimental design}

The experiment was carried out in two separate groups; A (non-diseased; $n=8$ ) and $B$ (diseased; $n=8$ ), making the total 16 mice in the experiment. Each mouse in the non-diseased group (A), were orally inoculated with $1.0 \mathrm{~mL}$ of sterile phosphate buffer saline (PBS), $\mathrm{pH}$ 7. In contrast, each mouse in the diseased group (B), were orally inoculated with $1.0 \mathrm{ml}$ of $10^{9}$ colony forming unit (CFU) of C. pseudotuberculosis. Within 120 hours after inoculation, clinical signs and mortality rates were observed in both groups. Mice showed severe clinical signs and survived mice after 120 hours post infection was sacrificed via cervical dislocation and post mortem examination was performed. Tissue samples were obtained from heart, lungs, lymph node, kidney, intestine and brain for histopathological study.

\section{Clinical signs and Scoring}

The clinical observations presented by the diseased and non-diseased groups were regularly documented from the start of the study until the end point of the experimental period. Scoring system was used to score the observational clinical signs. In summary, the clinical signs of the two groups (A \& B) were scored in scale of 0-3 based on the presence of following parameters: ruffled hair, eye discharge, movement and responsiveness. The score 0 represented no abnormality of clinical signs observed, 1 for mild, 2 for moderate, 3 for severe. The evaluation method of the scoring system was summarized in Table I.

Table I

Clinical Observation Scoring System

\begin{tabular}{|c|c|c|c|c|}
\hline \multirow[t]{2}{*}{ Parameters } & \multicolumn{4}{|c|}{ Clinical Score } \\
\hline & 0 & 1 & 2 & 3 \\
\hline Ruffled hair & Normal fur & $\begin{array}{l}\text { Ruffled fur by } 30 \% \text { of } \\
\text { the body }\end{array}$ & $\begin{array}{l}\text { Ruffled fur by } 60 \% \text { of } \\
\text { the body }\end{array}$ & $\begin{array}{l}\text { Ruffled fur more than } \\
60 \% \text { of the body }\end{array}$ \\
\hline Eye discharge & $\begin{array}{l}\text { No discharge from the } \\
\text { eyes }\end{array}$ & Eye discharge by $30 \%$ & Eye discharge by $60 \%$ & $\begin{array}{l}\text { Eye discharge more } \\
\text { than } 60 \%\end{array}$ \\
\hline Responsiveness & Normal responsiveness & $\begin{array}{l}\text { Reduced } \\
\text { responsiveness by } 30 \%\end{array}$ & $\begin{array}{l}\text { reduce responsiveness } \\
\text { by } 60 \%\end{array}$ & $\begin{array}{l}\text { reduce responsiveness } \\
\text { more than } 60 \%\end{array}$ \\
\hline
\end{tabular}

\section{Histopathology and lesion scoring}

Mice showed severe clinical signs and survived mice after $120 \mathrm{~h}$ post infection was sacrificed via cervical dislocation and post mortem examination was performed .Tissue samples were collected from the heart, lung, lymph nodes, liver, kidney, intestine and brain. Tissues were fixed with $10 \%$ formalin except for the brain tissue samples which were fixed with $40 \%$ formalin and processed in an automatic tissue processor and was routinely stained by haematoxylin and eosion for histopathology evaluation. Microscopically, cellular changes were scored following observation of 5 slides per organ. Six microscopic fields for each slide were observed at 200x magnification. Lesion scoring was divided into 4 scores; namely: score 0: normal (normal), score 1: mild (less than $30 \%$ of field involved), score 2: moderate (30-60\% of field involved) and score 3: severe (more than $60 \%$ of field involved).

\section{Statistical analysis}

The findings of the study were analysed by using the independent T-test. Significant difference between mean value of diseased group and non-diseased group was analysed using the SPSS version 19. 


\section{Clinical Signs}

\section{RESULTS AND DISCUSSION}

Animals both in diseased and non-diseased groups exhibited no clinical signs. Thus, the differences in the clinical scores of both groups were not significant $(\mathrm{P}>0.05)$ in the following parameters; ruffled hair coats, eye discharge, movement/depression and responsiveness.

These findings were not in agreement with those reported by [11]. In their findings, significant clinical signs in certain parameters such as ruffled hair, for instance, was found in mice that were inoculated intraperitoneally with $C$. pseudotuberculosis. Similarly, our findings differed from the experimental study conducted by [12], in which they stated that in some cases, infections with $C$. pseudotuberculosis do produce clinical signs. However, this could be attributed to the short period of observation ( 5 days) of the study and the effectiveness of different inoculation routes to produce significant clinical symptoms. Longer experimental period may normally allow diseases course (CLA) to be developed effectively and progression to be observed in other organs [13].

\section{Histopathological findings}

Microscopical examination of the visceral organs (Liver, lung \& Kidney) of the infected group revealed significant histopathological changes. The observed lesions were microscopically scored and summarized in Table 1I. Infiltration of neutrophils, macrophages, congestion, increased vascularisation, and haemorrhages in the alveolar lumen bronchiole and formation of micro abscesses were observed microscopically in lungs of the infected group (Fig. 1\& 2). Similar lesions were observed in the liver of mice treated with $C$. pseudotuberculosis where Infiltration of neutrophils and macrophages, degeneration, vacuolation (necrosis), haemorrhage and formation of micro abscesses were observed (Fig. $3 \& 4$ ). In mice treated with $C$. pseudotuberculosis, kidney showed evidence of haemorrhages, degeneration, congestion and tubular necrosis (Fig. 5-8).

The histopathological lesions observed in this study were similar to other experimental studies associated with CLA infections through different inoculation routes in sheep and goats. The findings of the present study were also consistent to those reported by [11]. However, the route of the infection differed in both studies. The hispathological lesions in the lung, liver and kidney do vary in response to the route of infection and character of innoculum; phospholipase D (PLD) and mycolic acid [14]. Phospholipase D (PLD), an exotoxin produced by $C$. pseudotuberculosisis, is a potent exotoxin that promotes the hydrolysis of ester bonds in mammalian cell membrane, resulting in the damage or destruction of host cell membranes, which may further lead to their dysfunction or disruption [15]. Moreover, PLD causes dermonecrotic lesions and is lethal to different species of laboratory and domestic animals at high doses [16]. Unlike PLD, mycolic acid also plays a major role in causing histopathological lesions in visceral organs. The production of localized swelling with congestion and necrosis often in the central area of haemorrhagic necrosis was reported in experimental infections with mycolic acid extracted from $C$. pseudotuberculosis[17]. Other experimental studies, using sheep and goats as models infected with $C$. pseudotuberculosis, showed the presence of pyogranulomatous lesions [18]. The less frequently infected tissues include heart, brain, spinal cord, testes, uterus and joints [18]. The spread of infection in the host might occur by the transfer of the bacterium via the blood or lymphatic system, resulting in the formation of lesions at other loci within the host [1]. Our results were in agreement with the experimental study conducted by [13] where infections with C. pseudotuberculosis developed lesions in liver, lungs, and kidney. In contrast, the extent of the severe lesions observed by [13] and [11] were not present in the present work. In this study, similar cellular changes were observed but the difference in the extent of the severity of the cellular changes may due to the short period of this study.

Table II

Scoring system for the lesions of visceral organs of mice after $120 \mathrm{~h}$ post inoculation with $C$. pseudotuberculosis.

\begin{tabular}{|c|c|c|c|c|c|c|}
\hline Organs & Groups & & & Parameter & & \\
\hline \multirow{3}{*}{ Lung } & & Oedema & $\begin{array}{l}\text { Inflammatory } \\
\text { cells }\end{array}$ & $\begin{array}{l}\text { Degeneration/ } \\
\text { Necrosis }\end{array}$ & Hemorrhage & Kupffer Cell \\
\hline & Control & $0.08 \pm 0.02$ & $0.10 \pm 0.04$ & $0.08 \pm 0.02$ & $0.12 \pm 0.06$ & NA \\
\hline & Treated & $1.38 \pm 0.97^{*}$ & $1.58 \pm 0.93^{*}$ & $1.46 \pm 0.72^{*}$ & $1.25 \pm 0.85^{*}$ & N/A \\
\hline \multirow[t]{2}{*}{ Liver } & Control & - & $0.08 \pm 0.02$ & $0.08 \pm 0.02$ & $0.12 \pm 0.06$ & $0.06 \pm 0.01$ \\
\hline & Treated & - & $1.58 \pm 0.65^{*}$ & $1.29 \pm 0.46^{*}$ & $1.21 \pm 0.66^{*}$ & $1.33 \pm 0.56^{*}$ \\
\hline \multirow[t]{2}{*}{ Kidney } & Control & - & $0.06 \pm 0.01$ & $0.08 \pm 0.02$ & $0.12 \pm 0.06$ & N/A \\
\hline & Treated & - & $1.25 \pm 0.68^{*}$ & $1.17 \pm 0.64^{*}$ & $1.50 \pm 0.51^{*}$ & N/A \\
\hline
\end{tabular}



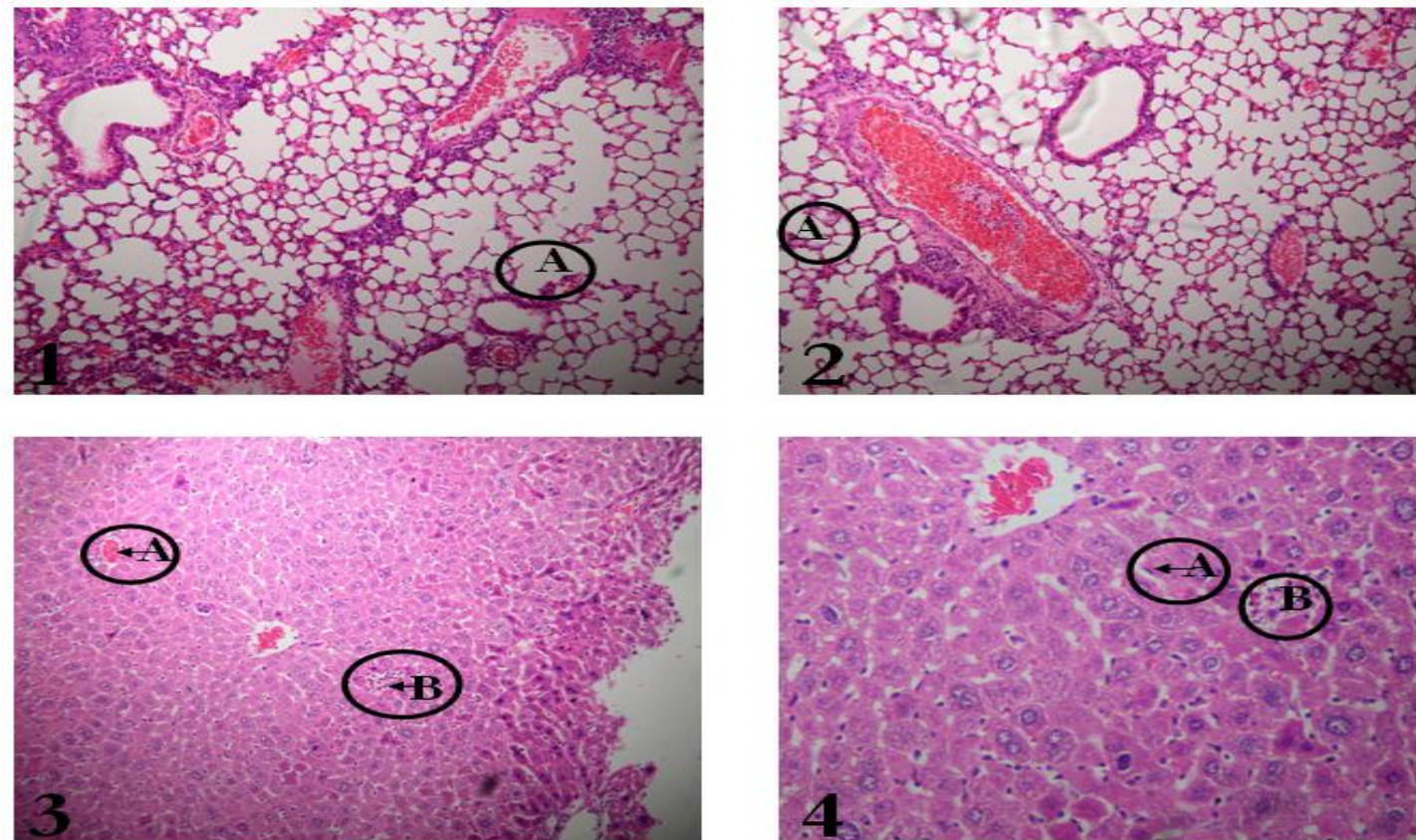

FIGURE 1.-Photomicrograph of a section of lung of mouse inoculated with C. pseudotuberculosis.Part of vascularization of the lung (A) (HE, X200). FIGURE 2.-Photomicrograph of a section of lung of mouse inoculated with $C$. pseudotuberculosis. Congested blood vessel lumen and massive influx of inflammatory cells (A) (HE, X200). FIGURE 3.-Photomicrograph of a section of liver of mouse inoculated with C. pseudotuberculosis. Markedly congested (A) and inflammatory cells (B) (HE, x100). FIGURE 4.-Photomicrogrpah of a section of liver of mice inoculated with C. pseudotuberculosis. Kupffer Cell (A) and Micro-abscesses formation (B). (HE, x200).
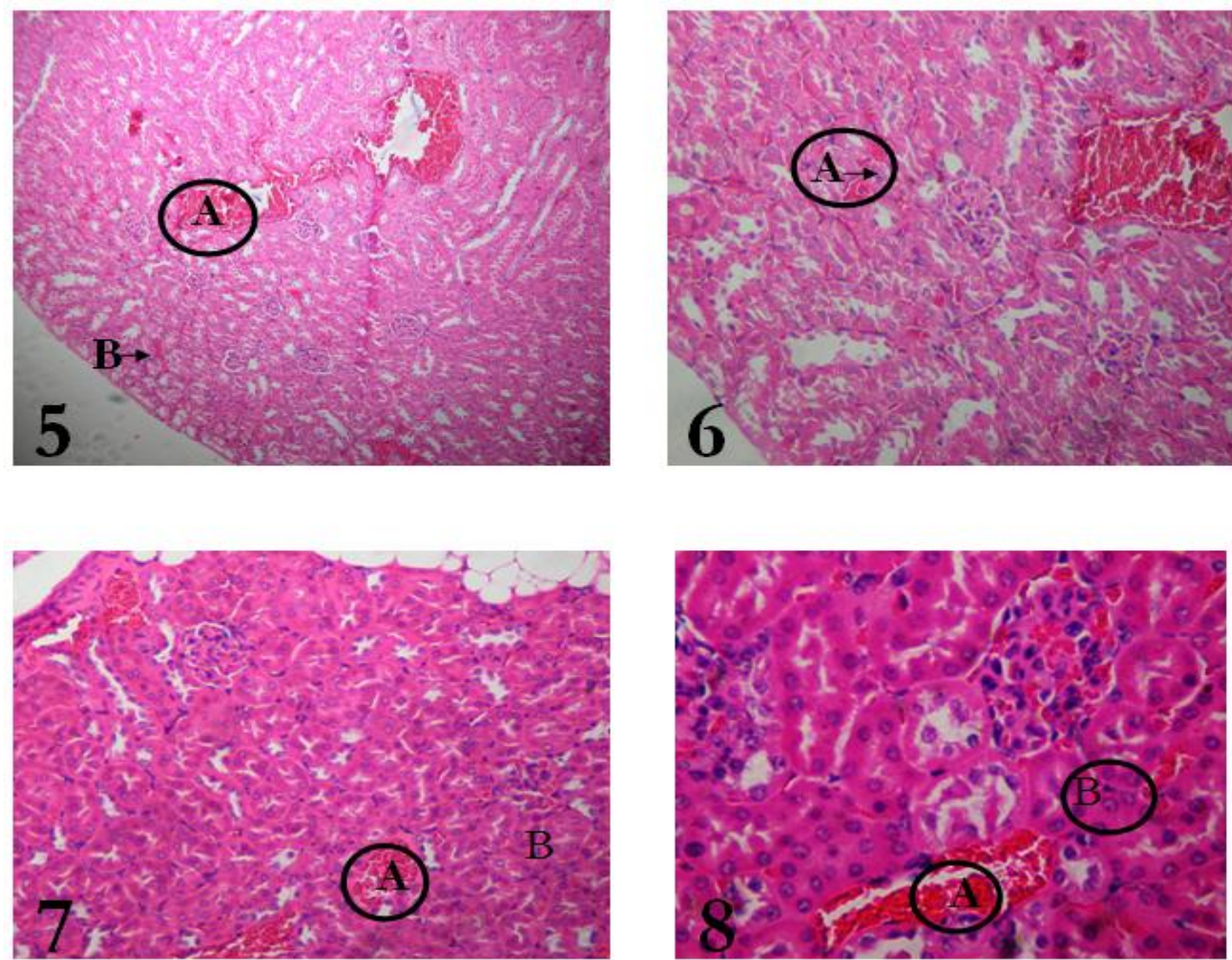

FIGURE 5.-Phototmicrograph of a section of kidney of mouse inoculated with C. pseudotuberculosis. Congestion (A).Intertubular haemorrhage (B) (He, x100). FIGURE 6.-Photomicrograph of a section of kidney of mouse inoculated with C. pseudotuberculosis. Severe intertubular haemorrhage and early signs of degeneration (A) (He, x200). FIGURE 7.-Photomicrograph of a section of kidney of mouse inoculated with $C$. pseudotuberculosis.Severe congestion (A). Signs of early degeneration (B) (He, x 200). FIGURE 8. - Photomicrograph of a section of kidney of mouse inoculated with C. pseudotuberculosis. Severe congestion (A). Signs of early degeneration (B) (He, x 400). 


\section{Conclusion}

This study revealed that oral exposure of live $C$. pseudotuberculosis resulted relatively establishment of CLA infection in a mouse model. The oral inoculation of C. Pseudotuberculosis in mice failed to produce the typical clinical signs of CLA but did produce significant histo-pathological changes that were characteristic of CLA.

\section{Declaration of Conflicting Interests}

The authors declared no potential conflicts of interest with respect the research, authorship, and/or publication of this article.

\section{Acknowledgments}

We thank Mr. Yap Keng Chee and Mr.Mohd Jefri Bin Norsidin for their excellent technical assistance. This investigation was financially supported by Ministry of Higher Education, Malaysia.

\section{References}

[1] Williamson, L.H. Caseous lymphadenitis in small ruminants. Veterinary Clinics of North America-Food Animal Practice, 17, 2001, 359-371.

[2] Binns, S.H., Bailey,M. andGreen, L. E. Postal survey of ovine caseous lymphadenitis in the United Kingdom between 1990 and1999.Veterinary Record, 150, 2002, 263-268.

[3] Baird, G.J., Fontaine, M.C. Corynebacterium pseudotuberculosis and its role in ovine caseous lymphadenitis. Journal of Comparative Pathology, 137, 2007, 179-210.

[4] Batey R.G. Pathogenesis of caseous lymphadenitis in sheep and goats. Australian Veterinary Journal, 63, 1986. $269-272$.

[5] Paton, M. W., Rose, I. R., Hart, R. A., Sutherland, S. S., Mercy, A. R., Ellis, T. M. and Dhaliwal, J. A. New infection with Corynebacterium pseudotuberculosis reduces wool production. Australian Veterinary Journal, 71, 1994, 47-49.

[6] Arsenault, J., Girard, C., Dubreuil, P., Daignault, D., Galarneau, J. R., Boisclair, J., Simard, C. and Belanger, D. Prevalence of and carcass condemnation from maedi-visna, paratuberculosisandcaseous lymphadenitis in culled sheep from Quebec, Canada. PreventiveVeterinary Medicine, 59, 2003, 67-81.

[7] Chan C.M. and Line S. The Merck Veterinary Manual.Merck Sharp \&Dohme Corp., Whitehouse Station NJ, USA, 2005.

[8] Piontkowski M.D and Shivvers D.W. Evaluation of a commercially available vaccine against Corynebacterium pseudotuberculosis for use in sheep. Journal of the American Veterinary Medical Association, 212, 1998, 1765-1768.

[9] Stanford K., Brogden K.A., McClelland L.A., Kozub G.C., Audibert F. The incidence of caseous lymphadenitis in Alberta sheep and assessment of impact by vaccination with commercial and experimental vaccines. Canadian Journal of Veterinary Research, 62, 1998, 38-43.

[10] Pekelder, J.J. Caseouslymphdenitis. En. In: Martin, W.B., Aitken, I.D. (Eds.), Diseases of Sheep, third ed. Blackwell Science, pp., 2000, 270-274

[11] Jesse F.F.A., Sang S.L., Saharee A.A. and Shahirudin S. Pathological Changes in the Organs of Mice Model Inoculated with Corynebacterium pseudotuberculosis Organism. Pertanika Journal of Tropical Agriculture Science, 34, $2011,145-149$.

[12] Brown C.C., Olander H.J. and Alves S.F. Synergistic hemolysis-inhibition titers associated with caseous lymphadenitis in a slaughterhouse survey of goats and sheep in Northeastern Brazil. Canadian Journal of Veterinary Research, 51, $1987,46-49$.

[13] Jennifer K., Gorman, Mourad G., James M.L., Nathan C.N., Janet E.F., Sharon J. S. Pilot Immunization of Mice Infected With an Equine Strain of Corynebacterium pseudotuberculosis. Veterinary Therapeutics, 11, 2010, 1-8.

[14] Hodgson A.L., Krywult J., Corner L.A., Rothel, J.S. and Radford A.J. Rational attenuation of Corynebacterium pseudotuberculosisçpotential cheesy gland vaccine and live delivery vehicle. Infection and Immunity, 60, 1992, $2900-2905$.

[15] Salyers A. and Witt D.Virulence factors that promote colonization. Bacterial Pathogenesis: a Molecular Approach. ASM Press, Washington, D.C., 1994,30-46.

[16] Songer J.G. Bacterial phospholipases and their role in virulence. Trends Microbiology, 5, 1997, $156-160$.

[17] Jolly R.D. Some observations on surface lipids of virulent and attenuated strains of Corynebacteriumovis. Journal of Applied Bacteriology, 29, 1966, 189-196.

[18] Valli V.E.O., Parry B.W., Caseouslymphadenitis.Jubb, K.V.F., Kennedy, P.C., Palmer, N. (Eds.), Pathology of Domestic Animals, vol. 3, 4th ed. Academic Press, San Diego, (993, 238- 240. 